\title{
Systemic Arterial Hypertension in the Emergency Service: medication adherence and understanding of this disease
}

\author{
Cássia Regina Vancini-Campanharo ${ }^{1}$ \\ Gabriella Novelli Oliveira² \\ Thaisa Fernanda Landim Andrade ${ }^{3}$ \\ Meiry Fernanda Pinto Okuno ${ }^{4}$ \\ Maria Carolina Barbosa Teixeira Lopes ${ }^{5}$ \\ Ruth Ester Assayag Batista ${ }^{6}$
}

Objective: to identify the epidemiological profile of hypertension patients, how much they understand about the disease and the rate of adherence to treatment by these patients who had been hospitalized in the Brazilian emergency service. Methods: this cross-sectional study was performed with 116 patients, both male and female and aged over 18 years, who had been hospitalized in the Emergency Service of a University Hospital between March and June, 2013. The studied variables were data referring to socio-demographics, comorbidities, physical activity and knowledge regarding the disease. Patient adherence to treatment and the identification of the barriers were respectively evaluated using the Morisky test and the Brief Medication Questionnaire. Results: most of the patients involved in this study were women (55\%), with white skin color (55\%), married (51\%), retirees or pensioners (64\%) and with a low educational level $(58 \%)$. Adherence to treatment, in most cases (55\%), was moderate and the most prevalent adherence barrier was recall (67\%). When medication was acquired at no cost to the patient, there was greater adherence to treatment. Conclusion: this study's patients had a moderate understanding about the disease. The high correlation between the number of drugs used and the recall barrier suggests that monotherapy is an option that can facilitate treatment adherence and reduce how often the patients forget to take their medication.

Descriptors: Hypertension; Therapeutics; Medication Adherence; Knowledge; Emergency Medical Services; Emergency Nursing.

\footnotetext{
1 Doctoral student, Escola Paulista de Medicina, Universidade Federal de São Paulo, São Paulo, SP, Brazil. RN, Escola Paulista de Enfermagem, Universidade Federal de São Paulo, São Paulo, SP, Brazil.

2 Master's student, Escola Paulista de Enfermagem, Universidade Federal de São Paulo, São Paulo, SP, Brazil. RN, Hospital Universitário, Universidade de São Paulo, São Paulo, SP, Brazil.

3 RN, Hospital São Paulo, Universidade Federal de São Paulo, São Paulo, SP, Brazil.

${ }^{4} \mathrm{PhD}$, RN, Escola Paulista de Enfermagem, Universidade Federal de São Paulo, São Paulo, SP, Brazil.

5 MSc, RN, Escola Paulista de Enfermagem, Universidade Federal de São Paulo, São Paulo, SP, Brazil.

${ }^{6}$ PhD, Adjunct Professor, Escola Paulista de Enfermagem, Universidade Federal de São Paulo, São Paulo, SP, Brazil.
}

Corresponding Author:

Gabriella Novelli Oliveira

Universidade Federal de São Paulo. Escola Paulista de Enfermagem

Rua Napoleão de Barros, 754

Vila Clementino

CEP: 04024-002, São Paulo, SP, Brasil

E-mail: novellioliveira@gmail.com
Copyright @ 2015 Revista Latino-Americana de Enfermagem This is an Open Access article distributed under the terms of the Creative Commons Attribution Non-Commercial License (CC BY-NC).

This license lets others distribute, remix, tweak, and build upon your work non-commercially, and although their new works must also acknowledge you and be non-commercial, they don't have to license their derivative works on the same terms. 


\section{Introduction}

Systemic Arterial Hypertension (SAH) is a public health problem that is characterized by a high prevalence and low treatment adherence rate, which is one of the major modifiable risk factors for Cardiovascular Diseases (CVDs). The main goal of treating SAH is to reduce cardiovascular morbidity and mortality ${ }^{(1)}$.

According to the World Health Organization (WHO), 17.3 million people died from CVDs in 2008, with 9.4 million of these deaths being due to complications arising from $\mathrm{SAH}$ in the same period. In addition, it is estimated that more than 23 million people will die as a result of CVDs by 2030(2-3).

One of the most important factors for effectively controlling Blood Pressure (BP) is patient adherence to treatment, given that 40 to $60 \%$ of patients with SAH do not use medication for such(4). Studies have shown that non-adherence to medication treatment, which is associated with medicine costs and patient sociodemographic conditions, is one of the main explaining factors for people demanding emergency services ${ }^{(5)}$.

There are many factors that can explain such non-adherence to SAH treatment, which makes it a complex and multidetermined phenomenon(2). These patients often have lower incomes, have difficulties accessing services, consume greater quantities of alcohol and undertake irregular medical follow-ups ${ }^{(2,6)}$. Thus, identifying non-adherence to antihypertensive treatment, as well as factors related to this condition, can make developing an intervention plan possible. The objective of this plan was to enhance adherence to treatment, reduce complications caused by $\mathrm{SAH}$ and decrease hospitalization numbers, which can reduce costs that have to be covered by the health system.

Therefore, this study's objective was to identify the epidemiological profile, the existing understanding regarding the disease and the barriers for non-adherence to the treatment by patients with $\mathrm{SAH}$, who had been hospitalized in the emergency room of a university hospital.

\section{Methods}

This cross-sectional study was performed from March 2013 to June of the same year in São Paulo Hospital's Emergency Service. São Paulo Hospital is the university hospital for the Federal University of São Paulo (UNIFESP) and cares for approximately 1000 patients at its Emergency Service on a daily basis.
The study was approved by the Research Ethics Committee from UNIFESP, under CAEE protocol number 13513713.0.0000.5505. Patients were permitted to be involved in this study after they had read and signed a Term of Free and Informed Consent (TFCC).

The non-probabilistic intentional sample was made up of 116 patients who had been hospitalized for more than 24 hours in the Emergency Service. These patients had to have had some kind of clinical or surgical diagnosis and personal history of SAH and been in drug treatment for at least one month. The patients were both male and female, aged over 18 years and had no cognitive impairment.

The researcher collected data from these patients by means of a questionnaire. The researcher read all the questions from the questionnaire to each patient in one meeting, with the mean time taken per interview being 25 minutes.

The variables studied were: age, gender, skin color, personal and family income, existence of associated diseases, physical activity level, weight, height, abdominal circumference, consumption of alcoholic beverages and understanding regarding the disease.

Any singular individual was classified as being physically active when he/she communicated undertaking aerobic physical activity such as: walking, running, cycling, dancing, swimming, at a 3 to 5 times a week frequency, with a 30-minute minimum duration ${ }^{(1)}$.

Weight and height data were collected verbally from the patient, the abdominal circumference was measured using a tape measure at the umbilical line level.

Alcoholic beverage consumption was considered excessive when it exceeded $30 \mathrm{~g}$ alcohol/day ${ }^{(1)}$.

Understanding regarding $\mathrm{SAH}$ was evaluated by means of the following questions: Do you think high blood pressure is a serious disease? In addition to medication, do you use any other types of treatment for high blood pressure? Do you think high pressure results in complications to your health? Do you think there is a cure for high blood pressure? Which factors do you think may be related to high blood pressure?

The Morisky test was used in order to evaluate patient adherence to treatment, this test consisted of four questions: 1) Do you ever forget to take your medicine? 2) Are you careless at times about taking your medicine? 3) Do you sometimes stop taking your drugs when you feel better? 4) Do you sometimes stop taking your drugs if they make you feel worse? A patient is classified in the high adhesion group when he/she gives negative four 
answers; in the medium adhesion group when he/ she gives one or two positive answers; and in the low adhesion group when he/she gives three or four positive answers(7).

In order to identify the barriers to treatment adherence, from the patients' perspective, the Brief Medication Questionnaire was used. This questionnaire is divided into three headings: the first evaluates the patient's behavior in relation to his/her adherence to a prescribed treatment regimen, the second assesses the patient's beliefs regarding the effectiveness of the treatment and opinions related to unwanted adverse effects, and the third heading identifies problems in relation to remembering to take the medication (recall). The presence of an affirmative response in each of the headings identifies a barrier to the prescribed treatment regimen, beliefs in the treatment and/or memory taking his/her medication $^{(8)}$.

The data was descriptively analyzed for the following variables: age, gender, skin color, personal and family income, existence of associated diseases, physical activity level, weight, height, abdominal circumference, consumption of alcoholic beverages and understanding regarding the disease. Frequency and percentages were used for categorical variables. Number of valid observations ( $\mathrm{n})$, mean, median, Standard Deviation $(\mathrm{SD})$, minimum and maximum values were presented for continuous numerical variables.

Analysis of variance (ANOVA) was used in order to compare the continuous variables with the adherence rate and with the barriers for non-adherence to the treatment by patients. The Chi-square test was used in order to compare the categorical variables with the adherence rate and with the barriers for non-adherence to the treatment by patients, and, when necessary, the Fisher's exact test or the likelihood ratio test was used. The considered level of significance was $p<0.05$.

\section{Results}

The mean patient age was 61.5 years old, most of whom were women (55\%), with white skin color $(55 \%)$, married (47\%) and retirees or pensioners (63\%). With regards to education level, the majority (59\%) had not completed primary education. The most common income level was between one and three Brazilian monthly minimum wages $(76 \%)$.

The most frequently reported comorbidities by patients were: Dyslipidemia (40\%) and diabetes mellitus
(34\%). The number of different classes of medications used by patients to treat SAH ranged from 1 to 5 drugs.

The sociodemographic characteristics and comorbidities of the patients included in this study can be seen in Table 1.

Table 1 - Distribution of hypertensive patients, according to their sociodemographic characteristics and comorbidities. São Paulo, SP, Brazil, 2013

\begin{tabular}{|c|c|}
\hline Characteristics & $N^{*}=116(\%)$ \\
\hline \multicolumn{2}{|l|}{ Age (years) } \\
\hline $\operatorname{Mean}\left(\mathrm{sd}^{\dagger}\right)$ & $61.5(14.8)$ \\
\hline \multicolumn{2}{|l|}{ Gender } \\
\hline Male & $52(45)$ \\
\hline Female & $64(55)$ \\
\hline \multicolumn{2}{|l|}{ Skin color } \\
\hline White & $64(55)$ \\
\hline Non white & $52(45)$ \\
\hline \multicolumn{2}{|l|}{ Marital status } \\
\hline Married & $55(47)$ \\
\hline Single & $18(16)$ \\
\hline Widowed & $24(21)$ \\
\hline Separated & $15(13)$ \\
\hline Other & $4(3)$ \\
\hline \multicolumn{2}{|l|}{ Occupation } \\
\hline Employed/self-employed & $26(23)$ \\
\hline Unemployed & $8(7)$ \\
\hline Work from home & $8(7)$ \\
\hline Retired/pensioner & $74(63)$ \\
\hline \multicolumn{2}{|l|}{ Education } \\
\hline No education & $8(7)$ \\
\hline Incomplete primary school & $68(59)$ \\
\hline Complete primary school & $12(10)$ \\
\hline Incomplete high school & $6(5)$ \\
\hline Complete high school & $12(10)$ \\
\hline Incomplete higher & $3(3)$ \\
\hline Complete higher & $7(6)$ \\
\hline \multicolumn{2}{|c|}{$\begin{array}{l}\text { Family income (number of monthly } \\
\text { minimum wages) }{ }^{\ddagger}\end{array}$} \\
\hline$<1$ & $9(8)$ \\
\hline 1 to 3 & $88(76)$ \\
\hline 3 to 5 & $(14)$ \\
\hline$>5$ & $3(2)$ \\
\hline
\end{tabular}

\footnotetext{
* Total number of patients

† Standard deviation

₹ Brazilian minimum monthly salary, in 2014: $R \$ 724,00$
}

In regards to blood pressure levels found in the patients, the mean systolic blood pressure was 126.3 $(28.8 \pm) \mathrm{mmHg}$ and the mean diastolic blood pressure was $81.2( \pm 19.3) \mathrm{mmHg}$. The mean heart rate was 79.2 ( \pm 17.7$) \mathrm{bpm}$. The mean abdominal circumference was $97.3( \pm 15.4) \mathrm{cm}$.

The most recognized SAH risk factors by patients were salt consumption (94\%), being overweight (89\%) and physical inactivity (88\%). 
The rate of patient adherence to treatment and the barriers to this adherence can be seen in Table 2, as evaluated by the Morisky test and the Brief Medication Questionnaire, respectively.

The majority of patients (56\%) presented a medium adherence to treatment, with the main barrier to this adherence being remembering to use the medication (recall), which was found in $67 \%$ of patients.

Table 3 shows the correlations between the sociodemographic and clinical variables of the patients and the variables from the Morisky test.

Upon analyzing the data regarding how the medication was acquired, patients for whom the drug was fully supplied without charge showed themselves to have a higher percentage of treatment adherence. Patients with dyslipidemia had a higher percentage of medium treatment adherence, while that for those without dyslipidemia had a higher percentage for low adherence.

Table 4 shows the correlations between sociodemographic and clinical variables of the patient and the understanding regarding the disease and the variables from the Brief Medication Questionnaire (BMQ).

When the regimen heading is compared with categorical variables, a higher percentage of treatment adherence in white patients can be identified, as is the case with those who believed that $\mathrm{SAH}$ is a serious disease.

In regards to the belief heading, patients with higher heart rates during the evaluation, patients who work from home, retirees/pensioners or the unemployed and physically inactive presented belief barriers regarding the effectiveness of the treatment and its adverse effects.

Table 2 - Rates of patient adherence to treatment and the types of barriers to this adherence, according to the Morisky test and the Brief Medication Questionnaire, respectively. São Paulo, SP, Brazil, 2013

\begin{tabular}{lc}
$\quad$ Rate of adherence/types of barrier & $\mathbf{n}(\%)$ \\
\hline Morisky test & $34(30)$ \\
High adherence & $65(56)$ \\
Medium adherence & $17(14)$ \\
Low adherence & \\
Brief Medication Questionnaire & $43(37)$ \\
Regimen barrier & $26(22)$ \\
Belief barrier & $78(67)$ \\
Recall barrier & \\
\hline
\end{tabular}

Table 3 - Correlation between the Morisky test and the sociodemographic and clinical variables. São Paulo, SP, Brazil, 2013

\begin{tabular}{|c|c|c|c|c|c|}
\hline \multirow[b]{2}{*}{ Sociodemographic and clinical variables } & \multicolumn{5}{|c|}{ Morisky test } \\
\hline & $\begin{array}{l}\text { High adherence } \\
\mathbf{N}^{*}(\%)\end{array}$ & $\begin{array}{c}\text { Medium } \\
\text { adherence } \\
\mathrm{N}(\%)\end{array}$ & $\begin{array}{c}\text { Low adherence } \\
\mathrm{N}(\%)\end{array}$ & $\begin{array}{c}\text { Total } \\
\text { N (100\%) } \\
\end{array}$ & p-value \\
\hline \multicolumn{6}{|l|}{ Medication acquisition } \\
\hline Fully supplied without charge & $28(38.4)$ & $35(47.9)$ & $10(13.7)$ & $73(62.9)$ & 0.0409 \\
\hline Paid for in total & $2(14.3)$ & $11(78.6)$ & $1(7.1)$ & $14(12.1)$ & \\
\hline Partially paid for & $4(13.8)$ & $19(65.5)$ & $6(20.7)$ & $29(25)$ & \\
\hline Total of patients & $34(29.3)$ & $65(56)$ & $17(14.7)$ & $116(100)$ & \\
\hline \multicolumn{6}{|l|}{ Dyslipidemia } \\
\hline Yes & $15(31.9)$ & $30(63.8)$ & $2(4.3)$ & $47(40.5)$ & 0.0322 \\
\hline No & $19(27.5)$ & $35(50.7)$ & $15(21.7)$ & $69(59.5)$ & \\
\hline Total of patients & $34(29.3)$ & $65(56)$ & $17(14.7)$ & $116(100)$ & \\
\hline
\end{tabular}

$* \mathrm{~N}=$ total number of patients 
Table 4 - Correlation between the headings from of the Brief Questionnarie Medication and sociodemographic, clinical and understanding of the illness by the patient variables in this study. São Paulo, SP, Brazil, 2013

\begin{tabular}{|c|c|c|c|c|}
\hline \multirow[b]{2}{*}{ Demographic variable } & \multicolumn{4}{|c|}{$\mathrm{BMQ}^{*}$ - regimen heading } \\
\hline & $\begin{array}{c}\text { Adherence } \\
\mathbf{N}^{+}(\%)\end{array}$ & $\begin{array}{c}\text { Potential non- } \\
\text { adherence } \\
\text { N (\%) }\end{array}$ & $\begin{array}{c}\text { Total } \\
\text { N(100\%) }\end{array}$ & p-value \\
\hline \multicolumn{5}{|l|}{ White Skin Color } \\
\hline Yes & $46(71.9)$ & $18(28.1)$ & $64(55.1)$ & 0.0269 \\
\hline No & $27(51.9)$ & $25(48.1)$ & $52(44.8)$ & \\
\hline Total of patients & $73(62.9)$ & $43(37.1)$ & $116(100)$ & \\
\hline \multicolumn{5}{|l|}{ Do you think the disease is serious? } \\
\hline Yes & $69(67.0)$ & $34(33)$ & $103(88.8)$ & 0.0152 \\
\hline No & $4(30.8)$ & $9(69.2)$ & $13(11.2)$ & \\
\hline Total of patients & $73(62.9)$ & $43(37.1)$ & $116(100)$ & \\
\hline \multirow{2}{*}{ Clinical variable } & \multicolumn{4}{|c|}{$\mathrm{BMQ}^{*}$ - Belief heading } \\
\hline & With barrier & With no barrier & Total & p-value \\
\hline \multicolumn{5}{|l|}{ Heart rate } \\
\hline Mean $\left(\mathrm{sd}^{\ddagger}\right)$ & $77.3(16.3)$ & $85.0(21.1)$ & $79.2(17.7)$ & 0.0317 \\
\hline Median (minimum-maximum) & $80.0(44-130)$ & $82.0(60-140)$ & $80.0(44-130)$ & \\
\hline Total of patients & 90 & 26 & 116 & \\
\hline \multicolumn{5}{|l|}{ Employment status } \\
\hline Employed & $14(93.3)$ & $1(6.7)$ & 15 & 0.0379 \\
\hline Unemployed & $6(75.0)$ & $2(25.0)$ & 8 & \\
\hline Self-employed & $11(100)$ & - & 11 & \\
\hline Retired/pensioner & $54(73.0)$ & $20(27.5)$ & 74 & \\
\hline Work from home & $05(62.5)$ & $3(37.5)$ & 8 & \\
\hline Total of patients & $90(77.6)$ & $26(22.4)$ & 116 & \\
\hline \multicolumn{5}{|l|}{ Physical activity } \\
\hline Active & $13(100)$ & - & 13 & 0.0387 \\
\hline Inactive & $77(74.8)$ & $26(25.2)$ & 103 & \\
\hline Total of patients & $90(77.6)$ & $26(22.4)$ & 116 & \\
\hline \multirow{2}{*}{ Understanding regarding the disease } & \multicolumn{4}{|c|}{$\mathrm{BMQ}^{*}$ - Recall heading } \\
\hline & With barrier & With no barrier & Total & p-value \\
\hline \multicolumn{5}{|l|}{ How many medications? } \\
\hline Mean (sd) & $1(0)$ & $2.06(0.8)$ & 1.75 & $<0.0001$ \\
\hline Median (minimum-maximum) & $1(1-1)$ & $2(1-5)$ & $1.5(1-5)$ & \\
\hline Total of patients & 38 & 78 & 116 & \\
\hline
\end{tabular}

* Brief Medication Questionnarie

† Total number of patients

₹ Standard deviation

Regarding the recall heading, patients who used a larger number of different drugs showed higher recall percentage barriers.

\section{Discussion}

In this study, most of the patients were female, had an mean age of 61.5 years and a low education level. These patients had an emergency service demand profile that was similar to other studies conducted with hypertensive patients in first aid units ${ }^{(4,9)}$. SAH is more common in men aged up to 50 years ${ }^{(10)}$, however, whenever more women are observed diagnosed with $\mathrm{SAH}$, it can be explained by the fact that women are more likely to seek health services, with a view to discover the diagnosis of the disease ${ }^{(11)}$.

Comorbidities diabetes mellitus and Dyslipidemia were present in 34 and $40 \%$ of the interviewees during this study, respectively. Besides $\mathrm{SAH}$, the presence of other comorbidities in the patients involved in this study can be linked to bad eating habits and lack of physical activity, which may give rise to the appearance of many chronic illnesses, which are often asymptomatic. Medical treatment, when arranged alongside lifestyle change, is the best way of reducing and preventing the damage generated by these chronic diseases ${ }^{(1)}$.

As regards the blood pressure levels found in this study, the mean systolic blood pressure was 126.3 
$\mathrm{mmHg}$ and the mean diastolic blood pressure was 81.2 $\mathrm{mmHg}$. These values were lower than those found in the literature. A similar study showed higher blood pressure levels, namely mean systolic blood pressure of 174 $\mathrm{mmHg}$ and mean diastolic blood pressure of $109 \mathrm{mmHg}$. This particular study also revealed that the patients treated in the first aid unit reported using controlled salt intake as a measure to control $\mathrm{SAH}^{(9)}$. Despite this similar study having reported this controlled salt intake, it did not describe how the patients controlled the amount of salt in their food(9). The fact that the mean blood pressure was lower in this similar study may be associated with the respondents having been hospitalized for over 24 hours in the emergency service, where they would have received antihypertensive therapy and restricted sodium intake through the low-sodium diet provided, which, according to the WHO, is $5 \mathrm{~g}$ of salt per day or $2 \mathrm{~g}$ of sodium(1).

The Morisky test classified most of the interviewed patients as being in the medium adherence group (56\%). The adherence rate found during this study is close to those found in the literature ${ }^{(12-13)}$. The medium and low antihypertensive treatment adherence may be associated to age, to using more than one different drugs to control blood pressure, and to lack of supervision and control of the disease(12,14). In addition, measuring patient treatment adherence is challenging, since there has been no consensus reached, from among the methods used, regarding which is the best method that can be considered the gold-standard(15-16).

In regards to the barriers for non-adherence to treatment, $67 \%$ of the patients presented a significant $(p<0.0001)$ barrier in the recall section of the BMQ when the patient was using more than one medication, of any class, to control his/her blood pressure. These data are in line with another study, which pointed out that the main reason for patients' non-adherence was due to them forgetting to use their medication ${ }^{(17)}$. These results indicate that the difficulty of patients remembering to take their medication is directly proportional to the number of drugs that they use. This suggests that monotherapy is a good strategy to encourage adherence to antihypertensive treatment ${ }^{(17)}$. Another study, performed at the basic health network in the Southern Region of Brazil, pointed out that the complex pharmacotherapy involved in treating $\mathrm{SAH}$ is one of the factors associated with non-adherence to drug treatment, followed by the dissatisfaction with the health service ${ }^{(18)}$.
The majority of interviewees ( $88 \%$ ) reported that they understand that hypertension is a serious illness. There was an observed significant correlation ( $\mathrm{p}=$ 0.0152 ) between the understanding of the disease's severity and a higher percentage of adherence in the regime heading of the $B M Q$, which may indicate that patients who do not believe in the seriousness of $\mathrm{SAH}$ have the lowest adherence percentages in this heading.

This study observed that when the medication was provided in full to the patient, there was a higher percentage of treatment adherence. This finding may be related to the low socioeconomic status of the studied population, who has difficulty meeting the treatment costs. One of the factors reported by patients as the reason for stopping their treatment is the high cost of medication associated with the lack of income to buy it, followed by forgetting to use it ${ }^{(9)}$. In contrast, one international study showed that the level of adherence to medication is higher when medical expenses are lower(19). Stimulating adherence to proposed treatment is necessary as is raising awareness surrounding the costs of non-adherence to treatment and to its impact on the health system.

Patients with no dyslipidemia have a higher percentage of low adherence to treatment, while those with dyslipidemia have a higher percentage of moderate adherence $(p=0.0322)$. The association between unbalanced nutrition, excessive consumption of sodium, carbohydrates and alcohol, physical inactivity and smoking are risk factors for the appearance of SAH and dyslipidemia; this set of factors that are related to the health of the individual contribute to this finding ${ }^{(1,20)}$.

Individuals who work from home, those who are retired/unemployed ( $p=0.0379)$ and inactive, in regards to undertaking physical activities $(p=0.0387)$, showed a higher percentage of belief barriers in relation to their drug treatment. This finding is similar to that made by other studies, in which there was an observed low adherence to medication treatment that are related to life habits, living with the restrictions the illness causes, financial situation and the availability of access to health services(17).

Among men and women with a low educational level, $\mathrm{SAH}$ is more common with increasing age, with it being higher for men up to the age of 50 years, which is twice as prevalent among non-whites with a predominance of black women as it is for white individuals ${ }^{(1,21)}$. 


\section{Conclusion}

Most of the hypertensive patients admitted to the emergency service were female, with low income and low education. These individuals showed that they had a moderate understanding of the disease and managed moderate treatment adherence, with the main barrier to this adherence being forgetfulness in terms of using their medication. When the medication was fully supplied without charge, the patients showed a higher percentage of treatment adherence. There was high correlation between the number of drugs used and the recall barrier, which suggests that monotherapy is an option that can facilitate treatment adherence and, in cases where this is not possible, it is necessary that the health team jointly look into other strategies with the patient so as to reduce how often the patients forget to take their medication.

There is no consensus in the literature regarding the best method to evaluate adherence to drug treatment. Direct methods, such as taking blood samples are costly and difficult to execute; indirect methods, such as questionnaires, can be considered and their results compared with studies that used other strategies. There is no method that is considered excellent, with the use of combined approaches often being required.

\section{References}

1. Sociedade Brasileira de Cardiologia/Sociedade Brasileira de Hipertensão/Sociedade Brasileira de Nefrologia. VI Diretrizes Brasileiras de Hipertensão. Arq Bras Cardiol. 2010;95 supl 1:1-51.

2. $\vee$ Diretrizes Brasileiras de Monitorização Ambulatorial da Pressão Arterial (MAPA V) e III Diretrizes Brasileiras de Monitorização Residencial da Pressão Arterial (MRPA III). Sociedades Brasileiras de Cardiologia, Hipertensão e Nefrologia. Arq Bras Cardiol. 2011;97 Supl 3:1-24.

3. Lim SS, Vos T, Flaxman AD, Danaei G, Shibuya K, Adair-Rohani $\mathrm{H}$, et al. A comparative risk assessment of burden of disease and injury attributable to 67 risk factors and risk factor clusters in 21 regions, 19902010: a systematic analysis for the Global Burden of Disease Study 2010. Lancet. 2012;380(9859):2224-60. 4. Barbosa RGB, Lima NKC. Índices de adesão ao tratamento anti-hipertensivo no Brasil e no mundo. Rev Bras Hipertens. 2006;13(1):35-8.

5. Davis DP, Jandrisevits MD, Iles S, Weber TR, Gallo LC. Demographic, socioeconomic, and psychological factors related to medication non-adherence among emergency department patients. J Emergency Med. 2012;43(5):773-85.

6. Castro VD, Car MR. Dificuldades e facilidades dos doentes no seguimento do tratamento da hipertensão arterial. Rev Esc Enferm USP. 1999;33(3):294-304.

7. Ben AJ, Neumann CR, Mengue SS. Teste de Morisky-Green e Brief Medication Questionnaire para avaliar adesão a medicamentos. Rev Saúde Pública. 2012;46(2):279-89.

8. Dewulf NLS, Monteiro, RA, Passos ADC, Vieira EM, Troncon LEA. Adesão ao tratamento medicamentoso em pacientes com doenças gastrintestinais crônicas acompanhados no ambulatório de um hospital universitário. Rev Bras Cienc Farm. 2006;42(4):575-84. 9. Cristiane SG, Pierin AMG, Junior DM. Comparação dos perfis de pacientes hipertensos atendidos em Pronto Socorro e em tratamento ambulatorial. Rev Esc Enferm USP. 2004; 38(1):90-8.

10. Kearney PM, Whelton M, Reynolds $K$, Muntner $P$, Whelton PK, He J. Global burden of hypertension: analysis of worldwide data. Lancet. 2005;365(9455):217-23.

11. Lima-Costa MF, Peixoto SV, Firmo JO. Validade da hipertensão arterial auto-referida e seus determinantes (Projeto Bambuí). Rev Saúde Pública. 2004;38(5):637-42.

12. Rajpura J, Nayak RJ. Medication adherence in a sample of elderly suffering from hypertension: evaluating the influence of illness perceptions, treatment beliefs, and illness burden. JMCP. 2014;19(1):58-65.

13. Girotto E, Andrade SMA, Cabrera MAS, Matsuo T. Adesão ao tratamento farmacológico e não farmacológico e fatores associados na atenção primária da hipertensão arterial. Ciênc Saúde Coletiva. 2013;18(6):1763-72.

14. Ross S, Walker A, MacLeod MJ. Patient compliance in hypertension: role of illness perceptions and treatment beliefs. J Hum Hypertens. 2004;18(9):607-13.

15. Santa Helena ET, Nemes MIB, Eluf-Neto J. Desenvolvimento e validação de questionário multidimensional para medir não-adesão ao tratamento com medicamentos.Rev Saúde Pública. 2008;42(4):764-7.

16. Borges JWP, Moreira TMM, Rodrigues MTP, Oliveira CJ. Utilização de questionários validados para mensurar a adesão ao tratamento da hipertensão arterial: uma revisão integrativa. Rev Esc Enferm USP. 2012;46(2):487-94.

17. Guedes MVC, Araujo TL, Lopes MVO, Silva LF, Freitas MC, Almeida PC. Barreiras ao tratamento da hipertensão arterial. Rev Bras Enferm. 2011;64(6):1038-42. 
18. Barretos MS, Reiners AAO, Marcon SS. Knowledge about hypertension and factors associated with the non-adherence to drug therapy. Rev. Latino-Am. Enfermagem. 2014;22(3):484-90.

19. Sokol MC, McGuigan KA, Verbrugge RR, Epstein RS. Impact of medication adherence on hospitalization risk and healthcare cost. Med Care. 2005;43(6):521-30.

20. Sociedade Brasileira de Cardiologia. V Diretriz Brasileira de Dislipidemias e Prevenção da Aterosclerose. Arq Bras Cardiol. 2013;101 Supl.1:1-22.

21.Ferreira SRG, Moura EC, Malta DC, Sarno F. Frequência de hipertensão arterial e fatores associados: Brasil, 2006. Rev Saúde Pública. 2009;43(2):98-106. 